\title{
A PRÁTICA DA LIBERDADE NO ESTADO MODERNO NAS CONCEPÇÕES DE JOHN LOCKE E JEAN-JACQUES ROUSSEAU
}

\author{
THE PRACTICE OF LIBERTY IN THE MODERN STATE ACCORDING TO THE IDEAS OF \\ JOHN LOCKE AND JEAN-JACQUES ROUSSEAU
}

LA PRÁCTICA DE LA LIBERTAD EN EL ESTADO MODERNO EN LAS CONCEPCIONES DE JONH LOCKE Y JEAN-JACQUES ROUSSEAU

Veralúcia Pinheiro ${ }^{1}$

Nilson Pereira Bezerra²

${ }^{1}$ Doutora em Educação pela UNICAMP. Docente do Programa de Pós-Graduação Interdisciplinar em Educação, Linguagem e Tecnologias da Universidade Estadual de Goiás (UEG), Anápolis, GO, Brasil. ${ }^{2}$ Mestre em Educação, Linguagem e Tecnologias pela Universidade Estadual de Goiás (UEG), Anápolis, GO, Brasil.

Resumo: Este artigo apresenta considerações sobre concepções de Estado, a partir do pensamento de dois pensadores clássicos, cujas formulações sobre o conceito de liberdade apresentam contribuições significativas para a compreensão dos princípios que regem o Estado Moderno. A primeira fundamenta-se na caracterização do liberalismo encontrado em Locke (1983), cuja concepção de liberdade está diretamente ligada ao direito à propriedade, tendo por base o poder econômico dos indivíduos. A segunda está ancorada no conceito de liberdade de Rousseau (1978: sd), que atribui o exercício da liberdade ao pleno direito individual de participação política e de igualdade jurídica sem distinção. O objetivo dessa análise é sistematizar as formulações teóricas destes pensadores acerca do processo de construção do Estado na modernidade, mediante a identificação e a problematização de argumentos que posteriormente serão utilizados para legitimar as ideologias que visam garantir sustentação à sociedade capitalista. Subjaz ainda a esse objetivo a intenção de refletir sobre o contexto em que se desenvolve a formação do sujeito na sociedade moderna, apto a reproduzir os valores e as concepções definidos pelas classes dominantes, limitando desse modo sua formação a sua inserção no mercado de trabalho.

Palavras-chave: Estado moderno; Igualdade social; Prática da liberdade.

\begin{abstract}
This article presents some considerations about the conceptions of State, based on the ideas of two classical thinkers, whose formulations on the concept of Freedom present significant contributions to the understanding of the principles that govern the Modern State. The first is based on the characterization of liberalism found in Locke (1983), whose conception of freedom is directly associated with the right to property, based on the economic power of individuals. The second is anchored in Rousseau's concept of Freedom (1978: sd), which attributes the exercise of freedom to the individual's full right to political participation and juridical equality, without distinction. The objective of this analysis is to systematize the theoretical formulations of these thinkers concerning the process of construction of the State in modernity, by identifying and investigating arguments that will later be used to give legitimacy to the ideologies that seek to guarantee sustainability for capitalist society. In addition to this objective, this work also reflects on the context in which the formation of the subject develops in modern society, which tends to reproduce the values and the conceptions defined by the dominant classes, thereby limiting the formation of these subjects to their participation in the labor market.
\end{abstract}


Keywords: Modern State; Social equality; Practice of Freedom.

\section{Resumen:}

Este artículo presenta consideraciones sobre las concepciones del Estado, a partir de la idea de dos pensadores clásicos, cuyas formulaciones sobre el concepto de libertad tienen importantes contribuciones a la comprensión de los principios que rigen el estado moderno. La primera se basa en la caracterización del liberalismo que se encuentra en Locke (1983), cuya concepción de la libertad está directamente relacionado con el derecho de propiedad basado en el poder económico de los individuos. La segunda está anclada en el concepto de libertad de Rousseau (1978: SD), que asigna el ejercicio de la libertad para el derecho individual a la participación política plena y la igualdad jurídica sin distinción. El propósito de este análisis es sistematizar las formulaciones teóricas de estos pensadores sobre el proceso de construcción del Estado en la modernidad mediante la identificación y el interrogatorio de los argumentos que será utilizado más adelante para legitimar ideologías que tienen como objetivo asegurar el apoyo a la sociedad capitalista. Subyace incluso este objetivo, la intención de reflexionar sobre el contexto en que se desarrolla la formación del sujeto en la sociedad moderna, capaz de reproducir los valores y conceptos definidos por las clases dominantes, lo que limita su formación para su inserción al mercado de trabajo.

Palabras Clave: Estado Moderno; La Igualdad Social; La Práctica de la Libertad.

\section{INTRODUÇÃO}

Este trabalho aborda duas fases de construção do Estado moderno com ênfase na perspectiva de liberdade, as quais nessa análise se revelam antagônicas entre si. No liberalismo caracterizado por Locke (1983) e no Estado social de Rousseau (sd), as relações humanas em sociedade são marcadas pelas disputas históricas entre indivíduos com interesses que se chocam, constituindo de um lado o grupo dominante e, do outro, o grupo que o primeiro se empenha em dominar. O liberalismo, conceituado por John Locke, se contrapõe ao Estado absoluto e esse posicionamento encontra-se na obra Segundo Tratado sobre o Governo, publicado primeiramente no ano de 1690 e republicado ao longo do tempo. Com base nos escritos da publicação do ano de 1983, este trabalho desenvolve uma discussão sobre o homem e sua organização social e revela uma concepção de liberdade não universal, mas de uma liberdade que é medida pelo poder econômico do indivíduo, fato que é rebatido por Rousseau (sd).

Jean-Jacques Rousseau publica no ano de 1762 'O Contrato Social', obra em que o autor se contrapõe ao Estado liberal de John Locke e que, a exemplo do ocorrido com a obra de John Locke, é republicada ao longo do tempo e aqui tomada como base para a crítica que se faz ao conceito de liberdade encontrada em Locke (1983). Esta abordagem tem o propósito de caracterizar o antagonismo histórico entre a pseudoliberdade encontrada no Estado liberal de Locke (1983) e a efetiva prática da liberdade, necessária na sociedade, preconizada por Rousseau (sd) no Estado socialista.

Com base nas divergências entre o Estado liberal de Locke (1983) e o Estado socialista de Rousseau (sd), elegeram-se como objeto de reflexão os conceitos de liberdade definidos pelos 
autores. De modo que, discutir-se-ão as relações do homem em sociedade, tendo como foco a categoria liberdade que, ao longo da história da modernidade, sofreu diversas interpretações, visando adequá-la às necessidades de manutenção desse modelo de sociedade. Tais dilemas na contemporaneidade se expressam nas ideologias que sustentam o neoliberalismo e consequentemente expressam também a falência do chamado Estado social.

\section{O ESTADO LIBERAL EM JOHN LOCKE}

O posicionamento contrário de Locke (sd) aos argumentos que buscam justificar a gênese da autoridade de um homem sobre o outro e sobre todas as coisas se deve ao fato de que esses pensamentos têm por base as Leis de Deus, que segundo o autor, não explicita tal direito e é, portanto, improcedente. Para fundamentar sua crítica, o autor cita como exemplo Robert Filmer, autor da obra patriarcha, publicada em 1680, na qual Filmer estabelece a gênese do poder absoluto da monarquia baseada no direito divino da descendência hereditária de Adão e dos patriarcas, o que é refutado por Locke no Primeiro Tratado Sobre o Governo, no qual ele diz que, "Para o homem, a escravidão é um estado tão vil, tão miserável e tão diretamente contrário ao temperamento generoso e à coragem de nossa nação, que é difícil imaginar como um inglês, e menos ainda um cavalheiro, poderia advogar em seu favor." (LOCKE, 2016, p. 22).

Locke (1983) afirma que a autoridade absoluta se apoia em bases falsas e questiona a veracidade do absolutismo, utilizando-se da própria argumentação a qual ele se opõe. Para o autor, o direito divino hereditário de Adão, no qual os defensores do absolutismo monárquico se apoiam, não foi delegado por Deus no ato de sua criação e ainda que assim o fosse, ter-seia aí um impasse, porque não se pode declarar uma antiguidade segura de linhagem, partindo de um ancestral comum. De modo que, partindo do princípio de que o homem não nasce mau e nem bom, para ele, o homem no estado de natureza é neutro com tendências a ser bom pelo desenvolvimento da razão, que o guiará no exercício do direito à vida. $O$ autor ressalta que, além do direito intrínseco à vida, o indivíduo goza também de outros direitos que lhe são atribuídos em função da razão, definidos como o direito à propriedade privada e o direito de punir, os quais devem ser gozados em observância às Leis da natureza e às leis de Deus.

Com relação às leis da natureza e às Leis de Deus, Locke (1983) estabelece que todos estão sujeitos a elas, independente da vontade e são essas leis que conferem ao indivíduo a liberdade que se contrapõe ao absolutismo monárquico de Robert Filmer. De acordo com estas reflexões, a menos que se queira fornecer argumentos àqueles que acreditam que todo:

governo terrestre é produto apenas da força e da violência, e que em sua vida em comum os homens não seguem outras regras senão as dos animais selvagens, em que o mais forte é quem manda, e assim justificando para sempre a desordem e a maldade, o tumulto, a sedição e a rebelião (coisas contra as quais protestam tão veementemente os seguidores dessa hipótese), será preciso necessariamente descobrir uma outra gênese para o governo, outra origem para o poder político e outra maneira para designar e conhecer as pessoas que dele estão investidas, além daquelas que Sir Robert Filmer nos ensinou. (LOCKE, 1983, p. 33).

Em relação à criação do Estado, Locke (1983) argumenta que, apesar da bondade 
existente no estado de natureza, ainda há uma carência de liberdade, pois o homem não participa da criação de nenhuma das leis a que está subordinado e a passagem do estado de natureza para a sociedade civil proporciona essa liberdade na medida em que a concessão dos seus direitos ao estado possibilita por meio do poder legislativo a criação das próprias leis. Pois cada vez que um homem entra na:

Sociedade civil e se torna membro de uma comunidade civil, renuncia a seu poder de punir ofensas contra a lei da natureza na realização de seu próprio julgamento particular, mas tendo delegado ao legislativo o julgamento de todas as ofensas que podem apelar ao magistrado, delegou também à comunidade civil o direito de requerer sua força pessoal. [...] Descobrimos aqui a origem dos poderes legislativo e executivo da sociedade civil, que é julgar, através de leis estabelecidas, a que ponto as ofensas devem ser punidas quando cometidas na comunidade social, e também determinar por meio de julgamentos ocasionais fundamentados nas presentes circunstâncias do fato, a que ponto as injustiças de fora devem ser vingadas, em ambos os casos empregando toda a força de todos os membros sempre que for necessário. (LOCKE, 1983, p. 88).

Nesse sentido, Locke (1983) aponta três elementos que vão concretizar a liberdade e promover a ordem na sociedade civil. Para o autor, a regulamentação das normas da convivência harmônica deve possuir o caráter de leis criadas pelos indivíduos, e são definidas como: leis estabelecidas, conhecidas, recebidas e aprovadas por consentimento. Sendo o estado de natureza carente de muitas condições, ele necessita também de uma lei amplamente reconhecida e legitimada para se constituir como padrão do certo e do errado e também para servir de medida comum para decidir as controvérsias. Tudo isso porque os homens são tendenciosos e não estão aptos a reconhecer o valor de uma lei que eles seriam obrigados a aplicar em seus casos particulares.

É diante dessa falta que Locke (1983, p. 87) compreende a necessidade de criação de um contrato social que estabeleça o direito de liberdade individual e é então que o Estado surge para garantir, formalmente, os direitos que o indivíduo já tem no estado de natureza referente à liberdade. Mas como nenhuma liberdade pode sobreviver sem ter em si o poder de preservar a propriedade e ao mesmo tempo punir os transgressores, é preciso que cada indivíduo renuncie ao poder natural e o deposite nas mãos da comunidade, confiando desse modo na proteção da lei.

Diferentemente do que ocorre na criação do Estado absoluto, na concepção de Hobbes (1998), em que há uma transferência dos direitos naturais do indivíduo para o Estado, aqui Locke (1983, p. 131) ressalta que há uma cessão dos direitos naturais do indivíduo para o Estado. Isso significa que o indivíduo possui seus direitos e os cede, temporariamente, ao Estado para que este aja em seu nome. Todavia, para o autor, embora os homens na sociedade renunciem à igualdade, à liberdade e ao poder executivo que possuíam no estado de natureza, o qual fora transmitido à sociedade, para que o legislativo deles disponha na medida em que o bem da sociedade assim o requeira, cada um age dessa forma somente com o objetivo de melhor proteger sua liberdade e sua propriedade, por isso não se pode jamais admitir que o poder da sociedade, ou o poder legislativo por ela instituído, vá além do bem comum.

Na criação do Estado liberal, Locke (1983) propõe a separação de poderes como forma de quebra do absolutismo e de garantia da liberdade individual pela intervenção mínima do Estado na vida do indivíduo com a limitação do poder. Tal poder deve se estruturar em 
três partes: Poder Executivo, com funções administrativas; Poder Legislativo, com funções de deliberar sobre a criação da lei; e, por último, o Poder Federativo, com funções de tratar das relações internacionais. Segundo o autor, a liberdade consiste em não se estar sujeito à restrição e à violência por parte de outras pessoas, sendo que nessa concepção somente a lei pode proteger o indivíduo contra qualquer modalidade de arbitrariedade.

O pensamento liberal de Locke (1983) se contrapõe ao Estado absolutista de Hobbes (1998), a partir da admissão da atuação mínima do Estado, como garantia do direito à liberdade individual. $\mathrm{O}$ autor destaca que quanto menor é a interferência do Estado, maior será a liberdade do indivíduo na vida em sociedade.

Para que o direito à liberdade fosse assegurado, o Estado deveria atuar minimamente na legislação, porque se houvesse uma atuação máxima do Estado, seria uma negativa ao direito da liberdade individual, compreendida por Locke (1983) como sinônimo dos direitos políticos. De acordo com o autor, para se compreender adequadamente o poder político e também conhecer sua origem, deve-se levar em conta em que estado todos os homens se acham naturalmente, sendo este um estado de perfeita liberdade para ordenar-lhe as ações e regular-lhes as posses e as pessoas conforme acharem conveniente, dentro dos limites da lei da natureza, sem pedir permissão ou depender da vontade de qualquer homem.

Esta liberdade formal institui o direito à propriedade, à igualdade e impede o avanço do absolutismo encontrado em Maquiavel (2010) e em Hobbes (1998), determinando um novo estágio do Estado moderno. As bases para o exercício da liberdade e da igualdade, sacramentadas no Estado moderno por Locke (1983), encontram refúgio no pensamento político e determinam o desenvolvimento de uma nova ordem mundial, com base nos preceitos difundidos pelos revolucionários franceses. Desse modo, em Locke (1983, p. 36) existe uma lei de natureza no estado de natureza para governar os indivíduos. Tal lei submete todos a razão e ao mesmo tempo ensina que somos todos iguais e independentes, que ninguém deve prejudicar a vida do outro em nenhum aspecto, seja na saúde, na liberdade ou nas posses.

Com a derrocada do Estado absoluto, representado pela monarquia e influenciado pelo pensamento de Nicolau Maquiavel, em O Príncipe (2010) e de Thomas Hobbes, em Liviatã (2003) e Do Cidadão (1998), o Estado liberal estabelece novas diretrizes para as relações em sociedade com base no modo de produção. A manufatura dá lugar à indústria e isto significará a atuação do capital, determinando um novo conceito de igualdade e de liberdade, fundamentado na meritocracia e na desigualdade supostamente natural dos indivíduos. É justamente a partir de um discurso sobre natureza humana que Locke (1983, p. 55) argumenta em favor das desigualdades sociais. Para o autor, a excelência dos talentos e dos méritos pode colocar alguns acima do nível comum, pois "o nascimento pode sujeitar alguns, e a aliança ou os benefícios podem sujeitar outros". Porém, nada disso afeta a igualdade de todos os homens e não impede que cada homem seja senhor de sua liberdade natural, sem depender da vontade nem da autoridade de outro homem.

Porém, a partir da intensificação do comércio, a indústria assume a responsabilidade de produção e, consequentemente, o domínio político pelos donos das indústrias. Em decorrência da ascensão burguesa, ficam estabelecidas novas relações de produção em que o servo do 
sistema feudal não mais dividirá a sua produção com o seu senhor, ele agora será pago pela sua força de trabalho. Dessa nova configuração do Estado moderno, surge o capitalismo e a relação do trabalho no modo de produção capitalista, representado de um lado pelo trabalhador assalariado, pobre e, do outro, o patrão burguês, rico, relação esta que intensifica o antagonismo entre domínio e subserviência.

Ao argumentar em defesa do direito à propriedade privada, Locke (1983, p. 48) introduz a categoria trabalho nas relações humanas como condicionante e estabelece a partir de então o que para o Estado liberal significará a dominação pela dependência do indivíduo aos meios de produção. Apesar disso, o autor não renuncia aos argumentos relacionados a Deus e à natureza, afirmando que "ao dar a ordem para subjugar as coisas, Deus habilitou o homem a se apropriar delas. A condição da vida humana, que necessita de trabalho e de materiais para serem trabalhados, introduz forçosamente as posses privadas".

Além da categoria trabalho, que Locke (1983) insere em suas análises sobre as sociedades civis, o comércio também é utilizado para sacramentar o direito à propriedade privada e prorrogar esse direito em função da durabilidade do dinheiro ou dos objetos com valor considerável. No estado de natureza, se a apropriação, naturalmente exercida, ocorresse de modo excessivo e resultasse na perda do que foi apropriado em excesso, como o apodrecimento de frutos e a putrefação da caça, etc. estava o indivíduo dessa ação passível de punição, porque com isso, segundo Locke (1983, p. 49), "ele estaria invadindo a terra de seu vizinho, pois seu direito cessava com a necessidade de utilizar estes bens e a possibilidade de deles retirar os bens para sua vida". Em face desta transgressão à Lei natural que determina o direito à propriedade, o autor aponta a atividade do comércio como uma atividade que regulamenta a ação predatória do indivíduo e justifica a subversão à Lei natural.

De acordo com essa perspectiva, para Locke (1983, p. 52), o indivíduo que colhesse cem alqueires de maçãs, por exemplo, adquiriria assim uma propriedade sobre elas; a mercadoria era sua desde o momento em que a havia colhido. Neste caso, ele só tinha de se preocupar em consumi-la antes que estragasse, senão isto significaria que ele havia colhido mais que a sua parte e, portanto, roubado dos outros; e, na verdade, era uma coisa tola, além de desonesta, acumular mais do que ele poderia utilizar. Se ele distribuísse a outras pessoas uma parte desses frutos, para que não perecessem inutilmente, esta parte ele também estaria utilizando; e se ele também trocasse ameixas que iriam perecer em uma semana por nozes que durariam um ano para serem comidas, não estaria lesando ninguém; ele não estaria desperdiçando a reserva comum nem destruindo parte dos bens que pertenciam aos outros enquanto nada se estragasse inutilmente em suas mãos. Se ele trocasse suas nozes por um pedaço de metal cuja cor lhe agradara, ou trocasse seus carneiros por conchas, ou a lã por uma pedra de brilhante ou por um diamante, e os guardasse com ele durante toda a sua vida, não estaria violando os direitos dos outros; podia guardar com ele a quantidade que quisesse desses bens duráveis, pois o excesso dos limites de sua Justa propriedade não estava na dimensão de suas posses, mas na destruição inútil de qualquer coisa entre elas.

Assim, observa-se a inserção de outra categoria nas relações humanas que, no Estado liberal, coloca-se como determinante para instituir a desigualdade social, porque, para Locke 
(1983, p. 53), o dinheiro se estabelece como uma "coisa duradoura que o homem podia guardar sem que se deteriorasse e que, por consentimento mútuo, os homens utilizariam na troca por coisas necessárias à vida, realmente úteis, mas perecíveis". Por isso, dessa possibilidade de compra e venda com acúmulo de dinheiro, surge o capitalismo e seu representante mais emblemático, o burguês.

O Conceito de Estado encontrado em Locke (1983; 2016) tem sua gênese estabelecida pela necessidade de formalizar a liberdade e a igualdade que o indivíduo já tinha, no estado de natureza, garantir o direito à vida e estabelecer o direito à propriedade privada pelo trabalho. Neste conceito de Estado, a propriedade excessiva é justificada pela ação do comércio que insere o dinheiro nas relações comerciais e relaciona as desigualdades sociais às desigualdades naturais dos indivíduos. Trata-se de um Estado liberal, com atuação mínima e com poderes limitados pela sua divisão em três poderes harmônicos e independentes na forma de executivo, legislativo e federativo.

Diante da conceituação de Estado, encontrada em Locke (1983), percebe-se que a classe burguesa, como detentora dos meios de produção e no uso de sua liberdade assegurada pelo Estado, determina e caracteriza as relações do modo de produção de modo que o cenário social será composto pelo deslocamento populacional da zona rural para a zona urbana, formando um excedente de mão de obra e a relação entre patrão e empregado será marcada por uma intensa exploração por parte do patrão, o qual estabelece longas jornadas de trabalho com um mínimo de remuneração.

Nessa nova relação do modo de produção, o pensamento socialista de Jean-Jacques Rousseau ganha corpo na organização dos trabalhadores da indústria que se mobilizam pela melhoria das condições de trabalho, porém é uma organização que se restringe ao ambiente de trabalho e, portanto, não possui amplitude social, o que ocorre somente com a perspectiva socialista de K. Marx, que ao assumir um caráter científico, coloca-se em uma posição capaz de discutir não só as relações de trabalho, mas também outras questões que decorrem dessa relação.

\section{O ESTADO SOCIAL EM JEAN-JACQUES ROUSSEAU}

Jean-Jacques Rousseau (1978; sd) parte do princípio da existência do estado de natureza e do estado de sociedade definidos em Nicolau Maquiavel (2010), em Thomas Hobbes (1998) e em John Locke (1983); porém o objetivo de Rousseau (sd) é analisar o aspecto jurídico do Estado, ou seja, ele parte da concepção do estado de natureza do homem, contextualiza esse homem no estado de sociedade e determina um terceiro momento para esse homem que é o Contrato Social, ou o Estado propriamente dito.

Rousseau (sd, p. 18), tal como o fazem Hobbes (1998) e Locke (1983), acredita que, no estado de natureza, o homem é livre e sem a presença do Estado, ele é senhor de si mesmo. Para este filósofo, a liberdade comum é uma consequência da natureza do homem. De modo que "sua primeira lei é a de velar pela própria conservação, seus primeiros cuidados são aqueles que deve a si mesmo e, assim que alcança a razão, sendo o único juiz dos meios 
adequados à sua conservação, toma-se, por isso, seu próprio senhor".

O homem no seu estado de natureza, para Rousseau (sd), se constitui num indivíduo bom e essa bondade resulta do fato de que no estado de natureza ele não é um ser sociável, ele vive isolado dos outros grupos e, como tal, desconhece o direito à propriedade, porém, pelo convívio social, ele se corrompe em função da necessidade de possuir. Esta passagem do estado de natureza ao estado

civil produz no homem uma mudança notabilíssima, substituindo em sua conduta o instinto pela justiça, e dando às suas ações a moralidade de que não dispunha anteriormente. É só então que, a voz do dever sucedendo ao impulso físico e o direito ao apetite, o homem, que até então apenas havia olhado para si mesmo, é forçado a agir tomando como base outros princípios e consultando sua razão antes de ser influenciado por suas tendências. Embora neste estado se prive de muitas das vantagens que frui da natureza, ganha outras de mesmo porte, suas faculdades se exercitam e se desenvolvem, suas ideias ganham amplitude, seus sentimentos se enobrecem, sua alma inteira se eleva a tal ponto que, se os abusos dessa nova condição não o degradassem frequentemente abaixo daquela de onde saiu, deveria bendizer incessantemente o instante feliz que o arrancou dela para sempre e que, de um estúpido animal e limitado, fez um ser inteligente e um homem. (ROUSSEAU, sd., p. 31).

Essa evolução social do homem se dá pelo contato entre grupos distintos, em função do crescimento populacional. Um crescimento que resulta no estado de sociedade e, consequentemente, na corrupção do indivíduo pela ciência de outros grupos que o leva a buscar para si, não mais o que ele precisa, mas o que ele imagina precisar no futuro. Para Rousseau (sd), é nesse momento que o homem deixa de ser bom, no seu estado de natureza, e passa a ser ruim, a partir do conceito de propriedade, dando origem aos conflitos sociais.

Com o surgimento do conceito de propriedade e dos conflitos que surgem em decorrência dele, fica estabelecida a necessidade de criar regras para garantir a propriedade privada e a manutenção da ordem, a qual, segundo Rousseau (sd, p. 26), se constitui como a gênese do Estado. Assim, como os homens não podem engendrar novas forças, mas somente unir e dirigir aquelas que já existem, não existe nenhum outro modo para se conservarem que o de formar por agregação um conjunto de forças que possa sobrepujar a resistência, de acioná-las para um único objetivo e fazê-las operar em concerto.

Mas a instituição desse Estado, segundo Rousseau (sd, p. 27), dependerá do consentimento individual e do emprego da força coletiva para um objetivo comum e esse poder de união será efetivado mediante o consenso instituído pelo Contrato Social. Por isso, é necessário encontrar uma "associação que defenda e proteja de toda força comum a pessoa e os bens de cada associado, e pela qual cada um, se unindo a todos, obedeça apenas, portanto, a si mesmo, e permaneça tão livre quanto antes. Este é o problema fundamental a que o Contrato Social dá a solução".

Para Rousseau (sd), o Estado se constitui como produto da vontade geral, sem a qual não há possibilidade da convivência em sociedade, pois cada um coloca sua pessoa e toda sua força sob a direção suprema da

vontade geral; e recebemos, enquanto corpo, cada membro como parte indivisível do todo. Imediatamente, em lugar da pessoa particular de cada contratante, este ato de associação produz um corpo moral e coletivo composto de tantos membros quantos são os votos da assembleia, e que recebe desse mesmo ato sua unidade sem eu comum, sua vida e sua vontade. Esta pessoa pública, que é formada destarte pela união de todas as outras, tinha antigamente o nome de cidade e agora o de república ou de corpo político, que é chamado por seus membros de Estado [...] Quanto aos associados, recebem coletivamente o nome de povo. (ROUSSEAU, sd., p. 28). 
Essa transição do estado de sociedade para o Contrato Social, na concepção de Rousseau (sd, p. 155), passa por quatro momentos distintos em que, num primeiro momento, o indivíduo adquire a consciência de que ele vive uma falsa liberdade, como resultado da vontade geral ${ }^{1}$, porque esta pode ser seduzida por interesses particulares que alguns homens hábeis, desfrutando do próprio crédito e da eloquência, saibam substituir pelos seus. Nesse sentido, Rousseau chama atenção de seus leitores para a necessidade de não se mirar na falsa democracia ateniense, a qual era governada por oradores e eruditos. Segundo o filósofo, ao se observar com cuidado o que acontece numa deliberação qualquer, ver-se-á que a vontade geral é sempre pelo bem comum, mas muito frequentemente se determina uma secreta cisão, um pacto tácito que, por objetivos particulares, leva à ilusão da orientação natural da assembleia. Então o corpo social se fragmenta e seus membros assumem uma vontade geral, boa e justa relativamente a estes novos corpos, mas injusta e má relativamente ao todo original.

O segundo momento se caracteriza na implantação de uma democracia direta sustentada na soberania inalienável ${ }^{2}$ e indivisível ${ }^{3}$ do povo, em que todos os indivíduos, independente da condição de gênero ou poder econômico, deliberam sobre as leis as quais todos vão se submeter. Para Rousseau (sd), o conceito de liberdade está na participação política efetiva, ou seja, o indivíduo será livre porque se submete à lei que ele próprio criou.

Ora, o soberano sendo formado apenas pelos particulares que os compõem, não tem nem pode ter interesse contrárioaoseu, consequentementeapotênciasoberananãotemnenhumanecessidadedegarantiafaceaseussúditos, porque éimpossível que o corpo deseje prejudicar a todos seus membros; o soberano, por apenas aquilo queé,é sempre oque deve ser[...] O soberano por apenas aquiloqueé,ésempre oque deve ser.(ROUSSEAU, sd.,p.30).

No terceiro momento considera-se a vontade geral ${ }^{4}$ com base nos princípios naturais do homem bom. Rousseau (sd, p. 49) enfatiza que o homem em seu estado de natureza é bom, mas é corrompido pela sociedade no momento em que ele passa a olhar para o fato concreto e seus princípios, que naturalmente são bons, são esquecidos. Portanto, o povo sempre deseja seu próprio bem, mas por si mesmo não o encontra sempre. A vontade geral sempre é correta, mas o julgamento que o guia nem sempre é esclarecido. Desse modo, é necessário fazer-lhe ver os objetivos tais como são, algumas vezes tais quais devem lhe parecer, mostrar-lhe o bom caminho, defende-lo contra as seduções das vontades particulares, aproximar de seus olhos os lugares e os tempos, contrabalançar a atração das vantagens presentes e sensíveis pelos perigos dos males afastados e ocultos.

O quarto momento é marcado pela criação da função do legislador, que atuará como conselheiro na criação e na execução da lei de maneira sábia e justa, respeitando-se a soberania do povo. Nesse sentido, conforme mostra Rousseau, para descobrir as melhores regras da sociedade que convêm às nações, seria necessária uma inteligência superior capaz de perceber todas as paixões dos homens, mas que não experimentasse nenhuma, que não tivesse nenhuma relação com nossa natureza e que a conhecesse a fundo e cuja felicidade fosse independente da nossa. Enfim, que no decurso do tempo fosse almejando uma glória afastada e, desse modo, pudesse trabalhar num século e fruir num outro (ROUSSEAU, sd, p. 51).

O pensamento rousseauneano formalmente contribuiu com o pensamento político e jurídico atual. Rousseau (sd) estabelece a soberania como função atribuída ao povo, que ele 
chama de soberania popular, para o autor, o povo é soberano, porque no Contrato Social ele não transfere e nem cede seu direito natural ao Estado e à atuação do governo restringe-se à execução das leis criadas. Assim, ficam garantidas a liberdade e a igualdade, fundamentadas nos preceitos da vontade geral, no sentido certo e justo. Portanto, a vontade geral apenas pode dirigir as forças do Estado tendo como finalidade o bem-estar coletivo.

Para Rousseau (sd), a soberania pertence ao povo e ela é inalienável, indivisível, infalível e absoluta. Ela é inalienável porque pertencerá sempre ao povo, e é indivisível, porque pertence ao povo em sua unicidade e não a grupos distintos, é infalível porque no conceito de vontade geral se admite a bondade natural do homem e o conhecimento do que é certo e errado e, consequentemente, a ação do homem será correta. A soberania popular será também absoluta porque se o homem age conforme a vontade geral, a sua soberania será justa e, como tal, nada nem ninguém deve se sobrepor a ela.

Quando Rousseau (1978) analisa a concepção de Estado em Locke (1983), ele observa que o direito à liberdade e à igualdade se limita à formalidade e que na prática. Esse direito não se concretiza devido às diferenças sociais, as quais estabelecem restrições ao acesso desses direitos em virtude das diferentes instituições.

Ora, se se fizer uma comparação entre a diversidade prodigiosa de educação e de gênero de vida que reina nas várias ordens do estado civil, e a simplicidade e uniformidade da vida animal, e selvagem, na qual todos se alimentam com os mesmos alimentos, vivem da mesma maneira e fazem exatamente as mesmas coisas, compreender-se-á quanto deve a diferença de um homem para homem ser menor no estado de natureza do que no estado de sociedade e quanto aumenta a desigualdade natural na espécie humana por causa da desigualdade de instituições. (ROUSSEAU, 1978, p. 257).

Para Rousseau (1978), quando Locke (1983) admite que as desigualdades naturais determinam as desigualdade sociais, há aí uma inverdade, considerando que, na espécie humana, existem dois tipos de desigualdades, uma de ordem natural ou física, que leva em consideração a estrutura do corpo que pode ser alto, baixo, forte, fraco, jovem, velho, etc., e a outra de ordem moral ou política, que depende de uma convenção que é estabelecida pelo consentimento e esta ligada à condição de ser rico, pobre, dominante, dominado.

Não se pode perguntar qual a fonte da desigualdade natural, porque a resposta estaria enunciada na simples definição da palavra. Pode-se, ainda menos, procurar a existência de qualquer ligação essencial entre essas duas desigualdades, pois, em outras palavras, seria perguntar se aqueles que mandam valem necessariamente mais do que os que o obedecem e se a força do corpo ou do espírito, a sabedoria e a virtude sempre se encontram, nos mesmos indivíduos, na proporção do poder ou da riqueza: tal seria uma boa questão para discutir entre escravos ouvidos por seus senhores, mas que não convém a homens razoáveis e livres, que procuram a verdade. (ROUSSEAU, 1978, p. 235).

Rousseau (1978) afirma que, no Estado liberal, todos são livres perante a lei, mas, na esfera econômica, o que há é a ausência de liberdade material e isso ocorre porque é a situação econômica do indivíduo que vai determinar até onde vai a sua liberdade formal, ou a sua falsa liberdade. $O$ autor identifica na instituição da propriedade privada a gênese dos conflitos sociais e a responsabiliza pela ocorrência dos conflitos que levaram o homem à criação do Estado.

O verdadeiro fundador da sociedade civil foi o primeiro que tendo cercado um terreno, lembrou-se de dizer isto é meu e encontrou pessoas suficientemente simples para acreditá-lo. Quantos crimes, guerras, assassínios, misérias e horrores não pouparia ao gênero humano aquele que, arrancando as estacas ou enchendo o fosso, 
tivesse gritado a seus semelhantes: "Defendei-vos de ouvir esse impostor; estareis perdidos se esquecerdes que os frutos são de todos e que a terra não pertence a ninguém”. (ROUSSEAU, 1978, p. 259, grifos do original).

Rousseau (1978, p.270), quando caracteriza as particularidades da criação do Estado moderno, faz referência a um legado, que ele define como "nefasto" para as sociedades posteriores. O autor afirma que a miséria do gênero humano se deve à forma primeira de constituição do Estado. Para o autor, a criação das leis e a consequente proteção da propriedade fornecem os instrumentos necessários para uma maior submissão dos pobres e a extensão do poder rico, destruindo, desse modo, a liberdade natural e fazendo da desigualdade um direito irrevogável.

A partir da crítica aos modelos de Estado em Maquiavel (2010), em Hobbes (1998; 2003) e em Locke (1983; sd), Rousseau (1978, p. 258) define o espírito da convivência em sociedade e enfatiza que "os laços da servidão são formados unicamente pela dependência mútua dos homens e pela necessidade recíproca que os unem, é impossível subjulgar um homem sem antes tê-lo colocado na situação de não viver sem o outro" e, com isso, o autor estrutura a proposta de mudanças para o Estado, que é definido por ele como a instituição do Contrato Social, no qual o homem sai do estado de sociedade e cria uma situação adequada.

\section{CONSIDERAÇÕES FINAIS}

No final do século XVIII e início do século XIX, ocorrem significativas transformações nas estruturas política, social e econômica do mundo ocidental. Estas transformações são reflexos da Revolução Francesa (1789) e da independência dos Estados Unidos da América (1776), que redirecionaram a organização do modo de produção e, consequentemente, a organização das sociedades. A Revolução Francesa, em particular, deve ser destacada pela sua importância nas transformações estruturais ocorridas na sociedade, porque é a partir dos ideais que a impulsionaram, que nas décadas subsequentes a divisão social do trabalho fica mais evidente, intensificando o enfrentamento dos dois elementos antagônicos da sociedade: o povo e os poderosos.

Contrapondo-se ao sistema feudal, a Revolução Francesa promove uma reestruturação política, social e econômica na França do final do século XVIII e institui, por meio do Estado liberal, novas relações de poder formalizadas na valorização da liberdade e da igualdade, porém se verifica no conceito de Estado liberal que essa liberdade e essa igualdade se limitam ao aspecto meramente formal, já que estão subordinadas ao poder econômico dos indivíduos.

Com base no que foi exposto, entende-se que o conceito de Estado, para Jean-Jacques Rousseau, passa pela concepção de uma instituição criada para mediar conflitos entre indivíduos livres, pela vontade geral, com a forma de governo centrada nos princípios democráticos e o poder soberano atribuído ao povo, que exerce a sua liberdade pela efetiva participação política.

Esta liberdade de que trata o autor se distingue de qualquer outra apresentada, em nossa exposição, em função da necessidade de se estabelecer a educação como condição sine qua non para a prática efetiva da liberdade, pois esta prática está intrinsecamente ligada 
à participação política dos indivíduos, que para exercer essa participação política, necessita da capacidade de identificar o problema, analisá-lo e propor sua solução. Ou seja, o indivíduo deve possuir a capacidade de pensar.

Supõe-se que a formação do indivíduo social atuante perpassa os saberes acadêmicos e se instala num modelo de formação universal que compreende a formação, a priori, do indivíduo para a vida e posteriormente para a atuação profissional que ele decidir desempenhar. No entanto, tal decisão não é livre, ao contrário dos pressupostos dos iluministas sobre o exercício pleno da liberdade na sociedade moderna. A submissão do homem ao trabalho assalariado se realiza a partir de um controle total e este controle retira toda a possibilidade de exercício da liberdade. Desse modo, seja na modalidade de ditadura totalitária, seja em sua versão democrática, o Estado moderno coloca em prática ações violentas que vão da tortura explícita ao autocontrole introjetado pelos meios de comunicação de massa. Não existe liberdade nestas sociedades, mas um sistema cujos indivíduos obedecem aos imperativos do capital.

\section{REFERÊNCIAS}

HOBBES, T. Do cidadão. (trad.): Renato Janine Ribeiro. 2. ed. São Paulo: Martins Fontes, 1998.

Leviatã. (trad.): João Paulo Monteiro; Maria Beatriz Nizza da Silva; Claudia Berliner. 1. ed. São Paulo: Martins Fontes, 2003.

LOCKE, J. Primeiro tratado sobre o governo civil. In: Segundo tratado sobre o governo civil. (trad.): Magda Lopes; Marisa Lobo da Costa. São Paulo: Editora Vozes. Sd.

Segundo tratado sobre o governo: Ensaio relativo à verdadeira origem extensão e objetivo do governo civil. (trad.): Jacy Monteiro. 3. ed. São Paulo: Abril Cultural, 1983.

MAQUIAVEL, N. O príncipe. São Paulo: Legatus Editora, 2010.

ROUSSEAU, J. J. Do contrato social: Discurso sobre a economia política. (trad.): Márcio Pugliesi; Norberto de Paula Lima. São Paulo: Hemus. Sd.

. Discurso sobre a origem e os fundamentos da desigualdade entre os homens. (trad.): Lourdes

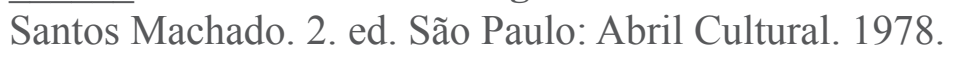

Artigo recebido em: 04/07/2017

Aprovado em: 18/12/2017

Contato para correspondência:

Veralúcia Pinheiro.E-mail: veraluciapinheiro27@gmail.com 
1 Rousseau se refere à vontade geral conceituada em Locke (1983), que se refere ao desejo unânime dos indivíduos, decisão pela maioria.

2 Afirmo então que a soberania sendo apenas o exercício da vontade geral, jamais pode ser alienada, e que o soberano, que é um ser coletivo, apenas pode ser representado por si mesmo: o poder pode ser transmitido, mas não a vontade (ROUSSEAU, sd., p. 37).

3 A soberania é indivisível pela mesma razão pela qual é inalienável; pois a vontade geral, ou não o é, a do corpo do povo, ou apenas de uma parte. No primeiro caso, esta vontade declarada é um ato de soberania e é lei; no segundo é uma vontade particular, ou um ato de magistratura, um decreto, no máximo (ROUSSEAU, sd., p.38).

4 Em sua obra, Do Contrato Social, Rousseau conceitua a vontade geral não como desejo unânime, mas como o agir certo, próprio do homem bom no seu estado de natureza. 